\title{
Analyzing screen heat insulation and its effect on energy consumption while heating building envelopes in conditions of intermittent heating
}

\author{
Yuri Vytchikov ${ }^{1}$, Mikhail Saparev ${ }^{1 *}$, and Alexandr Chulkov ${ }^{1}$ \\ ${ }^{1}$ Samara State Technical University, Institute of Architecture and Civil Engineering, \\ Molodogvardeyskaya str. 194, 443001 Samara, Russia
}

\begin{abstract}
Absract. The paper is devoted to screen heat insulation and its effect on energy consumption while heating building envelopes in conditions of intermittent heating. It also describes the non-stationary process of heat transfer through heat insulated outer walls. The authors introduce calculation results of specific energy consumption for heating insulated and non-insulted outer walls. The paper proves that energy consumption for heating insulated outer walls depends on the thickness of non-aerated air-space insulation The research shows positive effects of using thermal protection systems with screen thermal insulation in outer building envelopes in conditions of intermitten heating.
\end{abstract}

\section{Introduction}

Screen thermal insulation, apart from high thermal-shielding properties, has many other advantages. They are low bulk density, good moisture resistance, absence of odour and dust, applicability in the wide ranges of temperatures.

At the moment insulation materials of foamed polyethylene are widely used in civil engineering. These materials are protected by aluminum foil on one or both sides. Papers [1-6] prove that these insulation materials are effective, especially when combined with non-aerated air-space insulations. These papers describe the process of stationary heat transfer through building envelopes which are typical for buildings used in conditions of constant power heating.

Non-steady heat transfer process through building envelopes in conditions of intermittent heating is less known. Papers [7-18] describe these buildings thermal behaviour. To such buildings they refer country cottages, vacation homes and ski resorts and other buildings of full-time residence.

Thus, it is quite actual to introduce a new methodology of calculating building envelopes and assessing these buildings energy performance in conditions of intermittent heating.

* Corresponding author: $\underline{\operatorname{msx} 072007 @ \text { yandex.ru }}$ 


\section{Mathematical Modeling of Heat Transfer Process in Thermally Insulated Outer Wall}

In this research the authors study screen heat insulation effect on heating time and building envelopes energy consumption in conditions of intermittent heating. Figure 1 shows a scheme of the heating process through insulated outer walls by use of screen heat insulation.

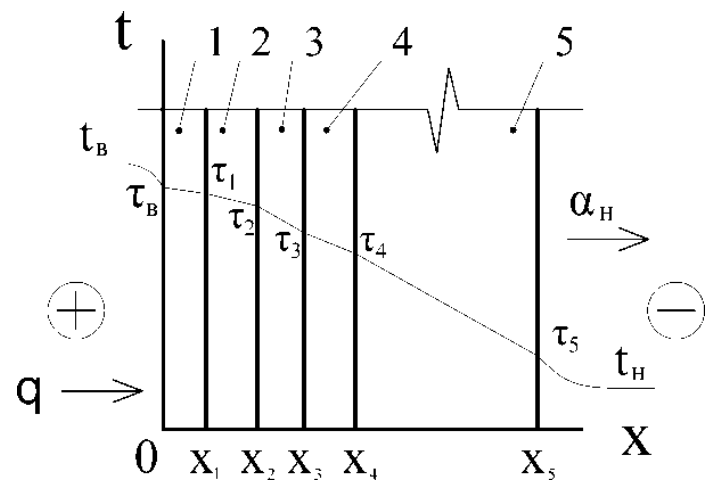

Fig.1. A scheme of the heating process through insulated outer walls: 1 - gypsum plasterboard; 2 non-aerated air-space insulation; 3 - foamed polyethylene protected by aluminum foil; 4 - sandcement mortar; 5 - laying of of small building products (bricks, building blocks).

Let us specify the problem of non-steady heat transfer in a insulated outer wall on the following assumptions:

- we neglect heat transfer in the direction if $\mathrm{Y}$ and $\mathrm{Z}$ axes, i.e. we consider the problem only in one dimension for the outer wall surface;

- we consider that there is a condition of perfect contact between the layers;

- we accept heat-transfer rate coming from heating appliances in the process of the outer wall heating as constant;

- we believe that in the initial time temperature distribution in the outer wall meets the stationary regime of background heating.

With account of these assumptions mathematical setting of the problem is as follows:

$$
\begin{aligned}
& -\lambda_{1} \frac{\partial t_{1}}{\partial x}=q ; x=0 \\
& \frac{\partial t_{1}}{\partial \tau}=a_{1} \frac{\partial^{2} t_{1}}{\partial x^{2}} ; x_{0} \leq x \leq x_{1} ; \tau>0 \\
& \frac{\partial t_{2}}{\partial \tau}=a_{2} \frac{\partial^{2} t_{2}}{\partial x^{2}} ; x_{1} \leq x \leq x_{2} ; \tau>0 \\
& \lambda_{1} \frac{\partial t_{1}}{\partial x}=\lambda_{2} \frac{\partial t_{2}}{\partial x} ; x=x_{1} \\
& t_{1}=t_{2}=\tau_{1} ; x=x_{1} \\
& \frac{\partial t_{3}}{\partial \tau}=a_{3} \frac{\partial^{2} t_{3}}{\partial x^{2}} ; x_{2} \leq x \leq x_{3} ; \tau>0 \\
& \lambda_{2} \frac{\partial t_{2}}{\partial x}=\lambda_{3} \frac{\partial t_{3}}{\partial x} ; x=x_{2}
\end{aligned}
$$




$$
\begin{aligned}
& t_{2}=t_{3}=\tau_{2} ; x=x_{2} \\
& \frac{\partial t_{4}}{\partial \tau}=a_{4} \frac{\partial^{2} t_{4}}{\partial x^{2}} ; x_{3} \leq x \leq x_{4} ; \tau>0 \\
& t_{3}=t_{4}=\tau_{3} ; x=x_{3} \\
& \frac{\partial t_{5}}{\partial \tau}=a_{5} \frac{\partial^{2} t_{5}}{\partial x^{2}} ; x_{4} \leq x \leq x_{5} ; \tau>0 \\
& t_{4}=t_{5}=\tau_{4} ; x=x_{4} \\
& \lambda_{4} \frac{\partial t_{4}}{\partial x}=\lambda_{5} \frac{\partial t_{5}}{\partial x} ; x=x_{4} \\
& -\lambda_{5} \frac{\partial t_{5}}{\partial x}=\alpha_{H}\left(\tau_{5}-t_{H}\right) ; x=x_{5} \\
& \left.t_{i}\right|_{\tau=0}=f_{i}(x) ; i=1 \div 5,
\end{aligned}
$$

where $f_{i}(x)$ - initial temperature distribution in conditions of background heating regular work; $t_{\text {out }}, t_{\text {in }}$ - air temperature inside and outside the building respectively, ${ }^{\circ} \mathrm{C} ; \tau_{i}-$ temperature in the joint of the layers, ${ }^{\circ} \mathrm{C} ; t_{i}$ - temperatures in the layers of outer walls, ${ }^{\circ} \mathrm{C} ; a$ - temperature conductivity coefficient of materials of the layer, $\mathrm{m}^{2} / \mathrm{sec} ; x_{i}$ - distance from the inner surface to the joints of the layers and the outer surface of the wall; $\lambda_{i}-$ temperature conductivity coefficient of outer walls layers, $\mathrm{W} /\left(\mathrm{m} \cdot{ }^{\circ} \mathrm{C}\right) ; \alpha_{H}$ - heat-exchange coefficient on the outer layers of building envelopes $\mathrm{W} /\left(\mathrm{m}^{2} \cdot{ }^{\circ} \mathrm{C}\right)$.

The equivalent coefficient of air temperature conductivity is determined from the formula

$$
\lambda_{2}=\lambda_{M} \varepsilon_{\kappa}+\alpha_{\pi} \delta_{2}
$$

where $\lambda_{\mu}$ is the air thermal conductivity coefficient, $\mathrm{W}\left(\mathrm{m}^{\circ}{ }^{\circ} \mathrm{c}\right) ; \varepsilon_{\kappa}$ - the correction factor, which takes into account the influence of natural convection; $\alpha_{n}$ - the coefficient of heat transfer radiation, $\mathrm{W} /\left(\mathrm{m}^{2} \cdot{ }^{\circ} \mathrm{c}\right)$.

Paper [3] gives a detailed methodology for determining coefficient $\varepsilon_{\kappa}$.

It does not seem possible to get the exact solution for the above differential equation system $(1) \div(15)$.

Paper [19] presents a formula for calculating one-layer building envelope heating time, using an analytical solution for a one-layer wall.

Specific energy consumption for heating a multi-layer construction can be calculated according to $[19,20]$.

\section{Results of Calculation Outer Walls Heating Time and Specific Energy Consumption}

Heating time for many-layers building envelopes can be calculated by using an approximate analytical method described in Papers [19, 20].

All the variants which are analyzed in these papers consider gypsum plasterboard with $\delta_{1}=0.02 \mathrm{~m}$, air-space insulation $\left(\delta_{2}=0.01 \mathrm{~m}\right)$, foamed polyethylene $\left(\delta_{3}=0.01 \mathrm{~m}\right)$, sandcement mortar $\left(\delta_{4}=0.015 \mathrm{~m}\right)$. Bearing layer here is a layer of silicate bricks on a sand- 
cement mortar of 510 and $640 \mathrm{~mm}$ thickness, as well as hollow ceramic brick of $510 \mathrm{~mm}$ thickness. The internal air temperature (with background heating working) $t_{61}$ is taken equal to $12{ }^{\circ} \mathrm{C}$, design temperature $t_{62}=22^{\circ} \mathrm{C}$; outer air temperature $t_{u}=-30^{\circ} \mathrm{C}$.

Table 1 present calculation results of outer walls heating time and specific energy consumption.

Table 1. Calculation results for insulated outer walls.

\begin{tabular}{|c|c|c|c|c|}
\hline $\begin{array}{c}\text { Variant № } \\
\text { for an } \\
\text { outer wall }\end{array}$ & Type of brickwork & $\begin{array}{c}\boldsymbol{R}_{\mathbf{0}}, \\
\left(\mathbf{m}^{\mathbf{2}} \cdot{ }^{\mathbf{C}} \mathbf{C}\right) \mathbf{W}\end{array}$ & $\begin{array}{c}\boldsymbol{\tau}_{\text {out }}, \\
\mathbf{h}\end{array}$ & $\begin{array}{c}\boldsymbol{Q}_{\text {out }}, \\
\mathbf{k J} / \mathbf{m}^{\mathbf{2}}\end{array}$ \\
\hline 1 & $\begin{array}{c}\text { Silicate brickwork on a sand-cement mortar } \\
\text { of 510mm thickness }\end{array}$ & 1.53 & 37.7 & $\frac{2245}{3656}$ \\
\hline 2 & $\begin{array}{c}\text { Silicate brickwork on a sand-cement mortar } \\
\text { of 640mm thickness }\end{array}$ & 1.70 & 56.4 & $\frac{3026}{4670}$ \\
\hline 3 & $\begin{array}{c}\text { Ceramic hollow brickwork on a sand-cement } \\
\text { mortar of 510mm thickness and 1400 kg/m3 } \\
\text { density }\end{array}$ & 1.74 & 42.9 & $\frac{2255}{3318}$ \\
\hline 4 & $\begin{array}{c}\text { Ceramic hollow brickwork on a sand-cement } \\
\text { mortar of 510mm thickness and 1300 kg/m3 } \\
\text { density }\end{array}$ & 1.84 & 42.0 & $\frac{2088}{2924}$ \\
\hline
\end{tabular}

Note. The denominator here presents values of specific energy consumption for non-insulated outer walls.

Specific energy consumption data given in Table one proves that screen thermal insulation considerably (27-39\%) allows to reduce energy consumption for outer walls heating.

The results of Studies [1,4] show that thermal resistance of screened air-space insulation depend on its thickness to great extent. The authors of this paper studied the dependence of air-space insulation thickness on energy consumption for outer walls heating. The study was conducted for one version of an outer wall. The thickness of air-space insulation varied from 0.01 to $0.03 \mathrm{~m}$. Figure 2 shows calculation results as the dependence of energy consumption for outer walls heating and air-space insulation thickness.

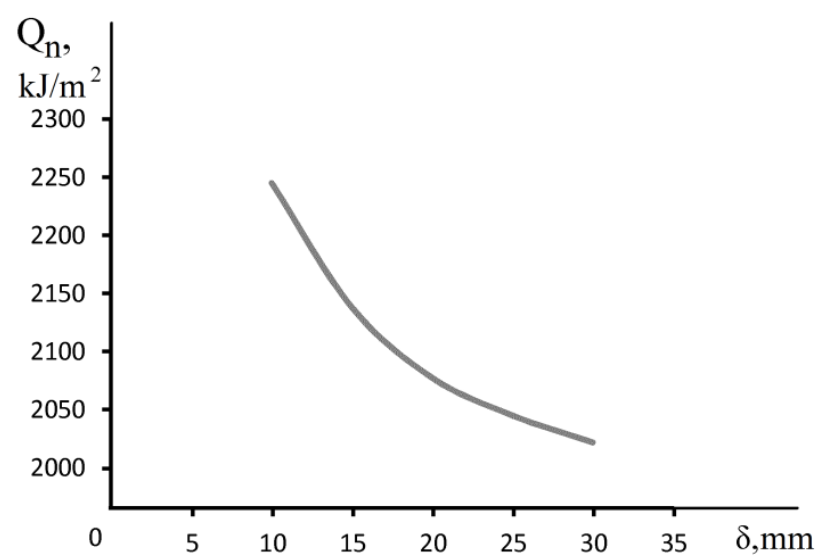

Fig.2. The dependence of energy consumption for outer walls heating and air-space insulation thickness. 


\section{Conclusions}

The research investigates screen heat insulation and its effect on heat-shield performance of outer walls as well as energy consumption for their heating.

The results of results of outer walls heating given in Table 1 prove that when a thermal protection system is installed heat transmission resistance increases approximately 1.5 times, and specific energy consumption is reduced from 27 to $39 \%$.

According to the obtained results, heating time for insulated outer walls (several variants of walls considered) constituted a significant amount of time (from 37.7 to $56.4 \mathrm{~h}$ ). Therefore, the authors recommend using an automatic remote control system with installed thermal generators for buildings used in conditions of intermittent heating.

When thickness of air-space insulation is increased from 10 to $30 \mathrm{~mm}$, energy consumption for heating of insulated outer walls is reduced by $10 \%$. So, it is recommended to construct outer walls insulated by screen thermal insulation while designing buildings which are planned to be used in conditions of intermittent heating.

\section{References}

1. Yu.S. Vytchikov, M.Ye. Saparev, Vestnik SGASU, Town Planning and Architecture 1, 4-7 (2016)

2. N.P. Umnyakova, House construction 1-2, 16-20 (2014)

3. V.I. Kovalevsky, G.P. Boykov, Thermal design of screen insulation and its methodology (Energy, Moscow, 1974)

4. Yu.S. Vytchikov, M.Ye. Saparev, Construction materials 11, 12-15 (2013)

5. Yu.S. Vytchikov, M.Ye. Saparev, Scientific Survey 2, 104-109 (2014)

6. Yu.S. Vytchikov, M.Ye. Saparev, Industrial and civil engineering 3, 52-55 (2014)

7. V.N. Bogoslovsky, Thermal behaviour of buildings (Stroiizdat, Moscow, 1979)

8. B.A. Semenov, Building envelopes heat insulation: non-steady heat transfer and effects (Saratov state technical university, Saratov, 1996)

9. E.Yu. Anisimova, Vestnik of South Ural State University, Civil engineering and architecture 38(297), 55-59 (2012)

10. E.G. Malyavina, R.R. Asatov, Thermal performance of outer building envelopes and their effect on heating system in conditions of intermittent heating, Academia, Architecture and civil engineering, 3, 324-327 (2010)

11. E.G. Malyavina, D.Yu. Pertov, House construction 6, 66-69 (2013)

12. V.I. Panferov, E.Yu. Anisimova, Vestnik of South Ural State University, Civil engineering and architecture 12(112), 30-37 (2008)

13. N.A. Datsuk, Yu.P. Ivlev, V.A. Pukhkal, Modern aspects of science and education 5, 179 (2014)

14. A.S. Gorshkov, P.P. Rymkevich, Magazine of Civil Engineering 8, 68-82 (2015)

15. A.S. Gorshkov, P.P. Rymkevich, N.N. Vatin, Magazine of Civil Engineering 8, 38-48 (2014)

16. T.N. Rubashkina, System analysis, Modelling 2, 188-195 (2014)

17. A.E. Zakharevich, Sanitary engineering, heating, conditioning 1, 64-67 (2014)

18. V.M. Lapin, AVOK: Ventilation, heating, air-conditioning, heat supply and building thermal physics 8, 48-51 (2012)

19. Yu.S. Vytchikov, I.G. Belyakov, M.Ye. Saparev, International research journal, Ekaterinburg 6, 42-48 (2016)

20. Yu.S. Vytchikov, I.G. Belyakov, M. Ye. Saparev, Procedia Engineering 153, 856-861 (2016) 